\begin{tabular}{l} 
SCIENCE \& TECHNOLOGY \\
Journal homepage: http://www.pertanika.upm.edu.my/ \\
\hline PERTANIKA
\end{tabular}

\title{
Flood-Modeling and Risk Map Simulation for Mae Suai Dam-Break, Northern Thailand
}

\author{
Anurak Busaman, Somporn Chuai-Aree, Salang Musikasuwan and \\ Rhysa McNeil* \\ Department of Mathematics and Computer Science, Faculty of Science and Technology, \\ Prince of Songkla University, Pattani 94000, Thailand \\ Centre of Excellence in Mathematics, CHE, Si Ayutthaya Rd., Bangkok, 10400, Thailand
}

\begin{abstract}
Dam-break floods are a serious disaster. This study aims to simulate and model the Mae Suai dam-break flood using shallow water equations (SWE) with an adaptive tree grid finite volume method, and determine the relationship between the initial water levels in the dam and the simulation results set regarding arrival times and maximum water depths using a polynomial model. We used elevation data obtained from the Shuttle Radar Topography Mission. The method was evaluated using the Xe-Pian dam-break flood simulation. The numerical results of water propagation was in agreement with the satellite image. The SWE and numerical algorithm was then used for the Mae Suai dam-break flood simulation. The numerical solution sets were approximated by a polynomial function of appropriate degree for flood arrival times and maximum water depth. Comparisons showed that the polynomial model results were similar to the SWE results; however, the proposed method was more efficient and can obtain a flood risk map without the need to fully solve the SWE. The method can also be applied for dam-break flood simulations and models in other regions using information from the dam.
\end{abstract}

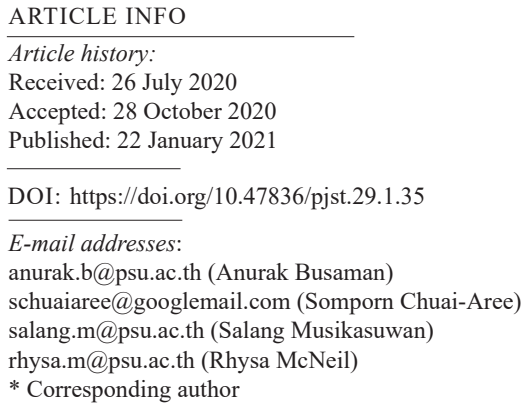

Keywords: Dam break, modeling, polynomial function, shallow water equations, simulation

\section{INTRODUCTION}

Dam-break floods are serious disasters. In 1959 the Malpasset dam-break in southern France, caused about 68 million dollars in terms of economic loss and resulted in 421 deaths (Goodman, 2013). In 2005, the Taum Sauk dam-break flood in the United States 
caused 1,100 fatalities (NOAA, 2005). In 2018, the Xe-Pian Xe-Namnoy dam-break flood in Laos resulted in 6,600 people becoming homeless and 98 people missing (Gong, 2018). Simulation and modeling of dam-break floods are necessary in order to provide information for planning, preparation, prevention and evacuation. For the simulation and modeling of the dam-break, George (2011) simulated Malpasset dam-break flood by solving the shallow-water equations with a finite a volume method and block-structured dynamic adaptive mesh refinement (AMR), while Dat et al. (2019) simulated dam-break flood inundation for a case study of DakDrinh Reservoir in Vietnam using 1D and 2D models of MIKE FLOOD. Moreover, Latrubesse et al. (2020) studied the cause of the Xe-Pian Xe-Namnoy dam breach, and assessed the hydrologic and geomorphic impact of the flood using the HEC-RAS 2D model to study flooding dynamics and dam-break flow.

Most of the dam-break simulations used numerical methods for solving the shallow water equations, which is time-consuming. And since the dam-break flood is a sudden flood, the results of the simulations may not be available in real-time. A mathematical model that can be run without fully running the numerical methods would be more practical. This can be performed by solving the model equations using the numerical method for some flood events and finding the relationship of the solution in the form of a simple model that can create the information for the dam-break in real-time.

In Thailand, an earthquake with a magnitude of 6.3 on the Richter scale occurred at Payao breakage in northern Thailand. The Payao breakage may have been caused by the earthquake and the dam-break at the nearby Mae Suai dam. This study was conducted for flood simulation and modeling for the case of Mae Suai dam break.

In a previous study, Busaman et al. (2015) developed the program to simulate and visualize the overland water flows by solving the shallow water equations using an adaptive tree grid finite volume method. This study modified this method in application for the dam-break flood simulation and modeling. Therefore, the objective of the study was to simulate Mae Suai dam-break flood using the shallow water equations with adaptive tree grid finite volume method, and assessed the relationship between initial water levels in the dam and the Mae Suai dam-break flood simulation results set regarding arrival times and maximum water depths using polynomial modeling.

\section{MATERIALS AND METHODS}

This study used a computational program (Busaman et al., 2015) written in Delphi Version 7 which could simulate and visualize in two and three dimensions animated views using the Open Graphics Library interface, including automatic generation of Keyhole Markup Language files for showing results via the Google Earth program. The program consists of numerical models and algorithms used to simulate and visualize the overland water flow. 


\section{Equations}

For the numerical models, the system of shallow water equations (SWE) was used to determine the behavior of overland water flow. The shallow water equations can be written as Equations 1, 2 and 3 (Cushman-Roisin \& Beckers, 2011).

$$
\begin{aligned}
& \frac{\partial h}{\partial t}+\frac{\partial u h}{\partial x}+\frac{\partial v h}{\partial y}=0 \\
& \frac{\partial u h}{\partial t}+\frac{\partial\left(u^{2} h+\frac{g}{2} h^{2}\right)}{\partial x}+\frac{\partial u v h}{\partial y}=-g h \frac{\partial z}{\partial x}-g h \frac{n^{2} u \sqrt{u^{2}+v^{2}}}{h^{4 / 3}} \\
& \frac{\partial v h}{\partial t}+\frac{\partial u v h}{\partial x}+\frac{\partial\left(v^{2} h+\frac{g}{2} h^{2}\right)}{\partial y}=-g h \frac{\partial z}{\partial y}-g h \frac{n^{2} v \sqrt{u^{2}+v^{2}}}{h^{4 / 3}}
\end{aligned}
$$

In the above equations, $h$ is the water depth, $u h$ and $v h$ represent the water discharge in the $x$ and $y$ directions, respectively, $u$ and $v$ are depth-averaged velocities in $x$ and $y$ direction respectively. For other variables, $g$ is gravitational acceleration, $z$ is topographic height, $t$ is time, and $n$ is the Manning's roughness coefficient. The equation can be written in a vector form as Equation 4:

$$
\partial_{t} H+\partial_{x} f(H)+\partial_{y} \mathrm{~g}(H)=-Z(H)-S(H)
$$

where $H=\left[\begin{array}{lll}h & u h & v h\end{array}\right]^{T} \quad$ is the dependent variable. $f(H)=\left[\begin{array}{lll}u h & u^{2} h+\frac{g}{2} h^{2} & u v h\end{array}\right]^{T}$ and $\mathrm{g}(H)=\left[\begin{array}{lll}v h & u v h & v^{2} h+\frac{g}{2} h^{2}\end{array}\right]^{T}$ are the flux functions in $\mathrm{x}$ and $\mathrm{y}$ directions, respectively. For the source terms, the gravity forces $Z(H)$ and friction forces $S(H)$ are represent by Equation 5:

$$
Z(H)=\left[\begin{array}{lll}
0 & g h \frac{\partial z}{\partial x} & g h \frac{\partial z}{\partial y}
\end{array}\right]^{T}
$$

and Equation 6

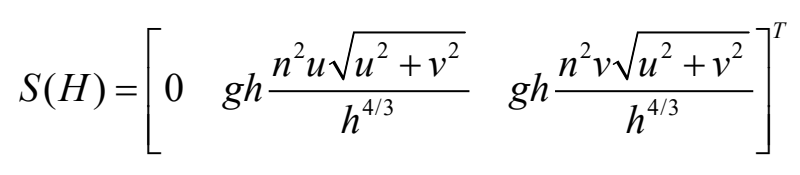

\section{Computational Details}

The shallow water equations were solved using a finite volume method. We adopted Addusse's discretization scheme (Audusse et al., 2004; Delestre et al., 2008). However, since the accuracy of overland water flow simulation depends widely on the usage of fine 
terrain grids, two dynamic grid techniques were adopted in our algorithm. First technique is to use a dynamically adaptive tree grid method, where the method continuously adjusts grid resolutions to follow features in the flow on the terrain. Second technique is the dynamic domain defining method (dynamic DDM) described by Yamaguchi et al. (2007). In this method, during the simulation, the area computation is expanded or shrunk to exclude dry grid cells. We developed the computational program by modifying adaptive tree grid techniques for rectangular quad tree grids, and combining them with the dynamic DDM.

For the computational program, Addusse's scheme can be applied for the discretization scheme on adaptive tree grids as Equation 7:

$$
H_{i}^{t+\Delta t}=H_{i}^{t}-\frac{\Delta t}{\Delta_{i}} \sum_{k} \hat{F}_{k}^{t} \cdot n_{k} \Delta \tau_{k}-\Delta t S_{i}^{t}
$$

where $\Delta t$ is the time step size; the subscript $i$ is the spatial index of each cell; $\Delta_{i}$ is the cell area; the subscript $k$ is the index for each sub interfaces over boundary between the cell and its neighbor, and $\Delta \tau_{k}$ is the width of the sub interface; $\hat{F}$ is the numerical fluxes, depending upon the chosen scheme; $n$ is the unit outward normal vector. In the discrete form, the gravity force is distributed to the numerical fluxes for each sub interfaces.

This method preserves the non-negative solutions of the water depth and also conserves the total water depth. Moreover, the scheme can compute dry states, and satisfies the still water properties.

The numerical scheme includes various techniques for best estimation. These techniques include a reconstruction procedure where each grid cell is estimated using the various quantities at interfaces between two adjacent cells using a min-mod slope limiter (Hagen et al., 2005) as Equation 8:

$$
Q_{k}^{-}=Q_{i}+\sigma_{k}\left(x_{k}-x_{i}\right)+\delta_{k}\left(y_{k}-y_{i}\right)
$$

where $Q=\left[\begin{array}{llll}h & u & v & h+z\end{array}\right]^{T}$ is the interpolated variable at each interface $k .\left(x_{i}, y_{i}\right)$ is the position of the cell, while $\left(x_{k}, y_{k}\right)$ is the position of each interface $k . \sigma_{k}$ and $\delta_{k}$ are minmod slope limiters at the position $\left(x_{k}, y_{k}\right)$ in $x$ and $y$ directions, respectively. The reconstruction procedure is performed for second order accurate scheme in space and helps to preserve the steady state and non-negativity of water depth. These quantities at interfaces are used for flux computation based on Harten, Lax and van Leer (HLL) flux as Equation 9:

$$
\hat{F}_{k} \cdot n_{k}=\frac{\alpha_{+} \hat{F}\left(U_{k}^{-}\right)-\alpha_{-} \hat{F}\left(U_{k}^{+}\right)+\alpha_{+} \alpha_{-}\left(U_{k}^{+}-U_{k}^{-}\right)}{\alpha_{+}-\alpha_{-}}+\hat{Z}\left(U_{k}^{-}\right) \cdot n_{k}
$$


where $\alpha_{ \pm}= \pm \max \left\{ \pm q_{k}^{-} \cdot n+\sqrt{g \hat{h}_{k}^{-}}, \pm q_{k}^{+} \cdot n+\sqrt{g \hat{h}_{k}^{+}}, 0\right\}$ are the wave speeds with the velocity vector, $q=\left[\begin{array}{ll}u & v\end{array}\right]^{T}$ and the vector of flux function $\hat{F}(U)=[f(U) \mathrm{g}(U)]^{T}$. In here, $\hat{Z}(U)=\left[\begin{array}{ll}z_{x} & z_{y}\end{array}\right]^{T}$ is the term to satisfy the balance of momentum flux and momentum gravity forces in the Audusse's scheme, when (Equation 10):

$$
z_{x}=\left[0, \frac{g}{2}\left(h_{k}^{-}\right)^{2}-\frac{g}{2}\left(\hat{h}_{k}^{-}\right)^{2}+g h_{i} z_{k}^{-}, 0\right]^{T}, \quad z_{y}=\left[0,0, \frac{g}{2}\left(h_{k}^{-}\right)^{2}-\frac{g}{2}\left(\hat{h}_{k}^{-}\right)^{2}+g h_{i} z_{k}^{-}\right]^{T}
$$

In these equations, $U_{k}^{ \pm}=\left[\hat{h}_{k}^{ \pm},(u \hat{h})_{k}^{ \pm},(v \hat{h})_{k}^{ \pm}\right]^{T}$ is the vector defined by the Audusse's scheme with the hydrostatic reconstruction (Zanotti \& Manca, 2010) given by Equation 11:

$$
\hat{h}_{k}^{ \pm}=\max \left\{0, h_{k}^{ \pm}+z_{k}^{ \pm}-\max \left\{\mathrm{z}_{k}^{-}, \mathrm{z}_{k}^{+}\right\}\right\}
$$

For second order accurate scheme in time is obtained using the second order total variation diminishing (TVD) method as Equation 12:

$$
\begin{aligned}
& H_{i}^{1}=H_{i}^{t}-\Phi\left(H_{i}^{t}\right) \\
& H_{i}^{2}=H_{i}^{1}-\Phi\left(H_{i}^{1}\right) \\
& H_{i}^{t+\Delta t}=\frac{H_{i}^{t}+H_{i}^{2}}{2}
\end{aligned}
$$

where $\Phi\left(H_{i}\right)=-\frac{\Delta t}{\Delta_{i}} \sum_{k} \hat{F}_{k} \cdot n_{k} \Delta \tau_{k}$ is the process of the numerical fluxes, the superscript 1 and 2 are the iteration steps. The TVD method can help reduce oscillation in the solution.

Moreover, in order to ensure stability, we also used a semi-implicit method for the friction forces (Delestre et al., 2008) as Equation 13:

$$
u h_{i}^{t+\Delta t} \leftarrow \frac{u h_{i}^{t+\Delta t}}{1+\Delta t \frac{g n^{2} \sqrt{\left(u_{i}^{t}\right)^{2}+\left(v_{i}^{t}\right)^{2}}}{\left(h_{i}^{t+\Delta t}\right)^{4 / 3}}}, v h_{i}^{t+\Delta t} \leftarrow \frac{v h_{i}^{t+\Delta t}}{1+\Delta t \frac{g n^{2} \sqrt{\left(u_{i}^{t}\right)^{2}+\left(v_{i}^{t}\right)^{2}}}{\left(h_{i}^{t+\Delta t}\right)^{4 / 3}}}
$$

For boundaries conditions, the opened boundaries conditions were used in this work as Equation 14: 


$$
h_{m}=h_{n}, u_{m}=u_{n}, v_{m}=v_{n}, z_{m}=z_{n}
$$

where the subscripts $m$ is the spatial index of the boundary cells, and $n$ are referred to as fictitious cells outside the computational domain.

This numerical algorithm is more efficient because it reduces the number of computational grid cells and computational times while preserving accuracy. The content in detail of the numerical schemes and algorithms for our software has been proposed by Busaman (2014). The adaptive tree grid finite volume algorithm was used in this work for solving SWE for Mae-suai dam-break simulation for each initial dam water levels of 472 to 509 meters. These initial water levels were set following historical data from Mae-suai dam, which were $427 \mathrm{~m}$ for the lowest water level and $509 \mathrm{~m}$ for the spillway level. The SWE simulation results set would be adopted for finding the relationship between the arrival times and maximum water depths using polynomial models as presented in the next section.

\section{Arrival Time Model}

For arrival times, we created a model using a 5-degree polynomial applied for each grid point. The arrival time is shown by Equation 15:

$$
A_{i, j}(W)=\beta_{5, i, j} W^{5}+\beta_{4, i, j} W^{4}+\beta_{3, i, j} W^{3}+\beta_{2, i, j} W^{2}+\beta_{1, i, j} W+\beta_{0, i, j}
$$

where $A_{i, j}(W)$ is the arrival time at each grid point $(i, j)$ for an initial water level in the dam $W$ and $\beta_{0, i, j}, \beta_{1, i, j}, \ldots, \beta_{5, i, j}$ are the coefficients of the model for each $(i, j)$.

\section{Maximum Water Depth Model}

The maximum water depth can be modeled using a 5-degree polynomial applied for each grid point. The maximum water depth is shown in Equation 16:

$$
M_{i, j}(W)=\gamma_{5, i, j} W^{5}+\gamma_{4, i, j} W^{4}+\gamma_{3, i, j} W^{3}+\gamma_{2, i, j} W^{2}+\gamma_{1, i, j} W+\gamma_{0, i, j}
$$

where $M_{i, j}(W)$ is the maximum water depth at $(i, j)$ for an initial water level in the dam $W$ and $\gamma_{0, i, j}, \gamma_{1, i, j}, \ldots, \gamma_{5, i, j}$ are the coefficients of the model for each $(i, j)$.

\section{Flow Diagram of Simulation}

This simulation was divided into two parts as shown in Figure 1. The first part was the SWE simulation for initial dam water levels of 472 to 509 meters, and consisted of 4 steps as follows. Step 1: solving the results from SWE for each initial water level in the dam. 


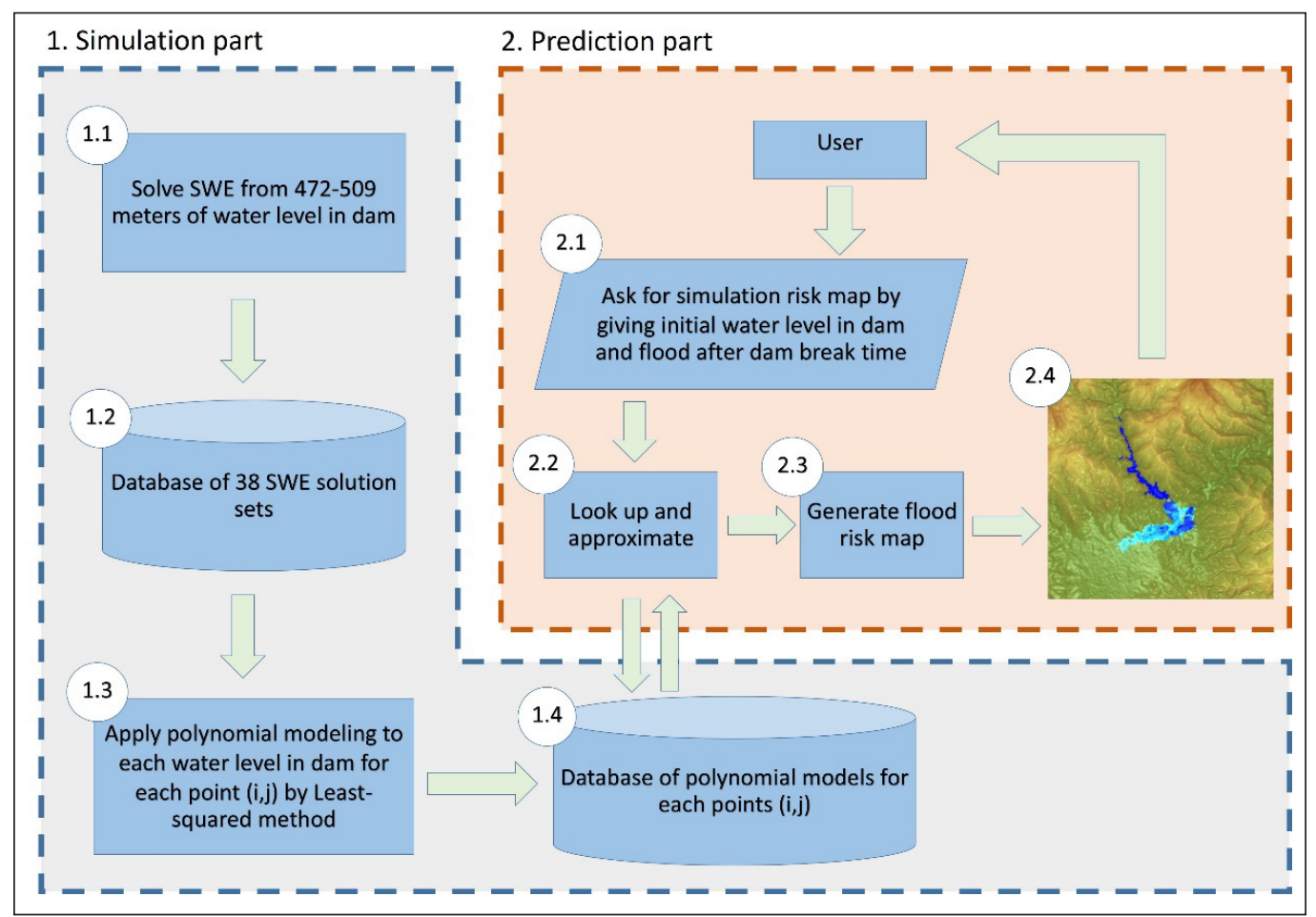

Figure 1. Flow diagram of simulation

Step 2: storing the arrival times and maximum water depth of the results in step 1 for each initial water level in the dam. Step 3: using least squares for parameter estimation of the coefficient value in the polynomial Equations 5 and 6 for each grid point (i, j), and Step 4: storing the coefficient values in a database for implementation in the second part. For the second part, there are 4 steps. Step 1: allowing the user to define inputs, which are the initial water level in the dam and flood after time the dam-break. Step 2: to approximate the arrival times and maximum water depth using the polynomial models stored in the database from Step 4 part 1. Step 3: to generate a flood risk map using the polynomial model results. Finally, Step 4 shows the flood risk map results to the user.

\section{Simulation for Mae Suai Dam-Break flood}

The simulation used digital terrain data $54,000 \mathrm{~m} \times 54,000 \mathrm{~m}$, generated from the SRTM data source. The data grid size was $600 \times 600$ cells. The location of Mae Suai dam and the land use map for this simulation is shown in Figure 2. Each of the grid cells are defined using Manning's coefficients by land use types as shown in Table 1 (Hunukumbura et al., 2007).

For the numerical solutions, the shallow water equations were solved using the adaptive finite volume method. The simulation was performed on the domain 


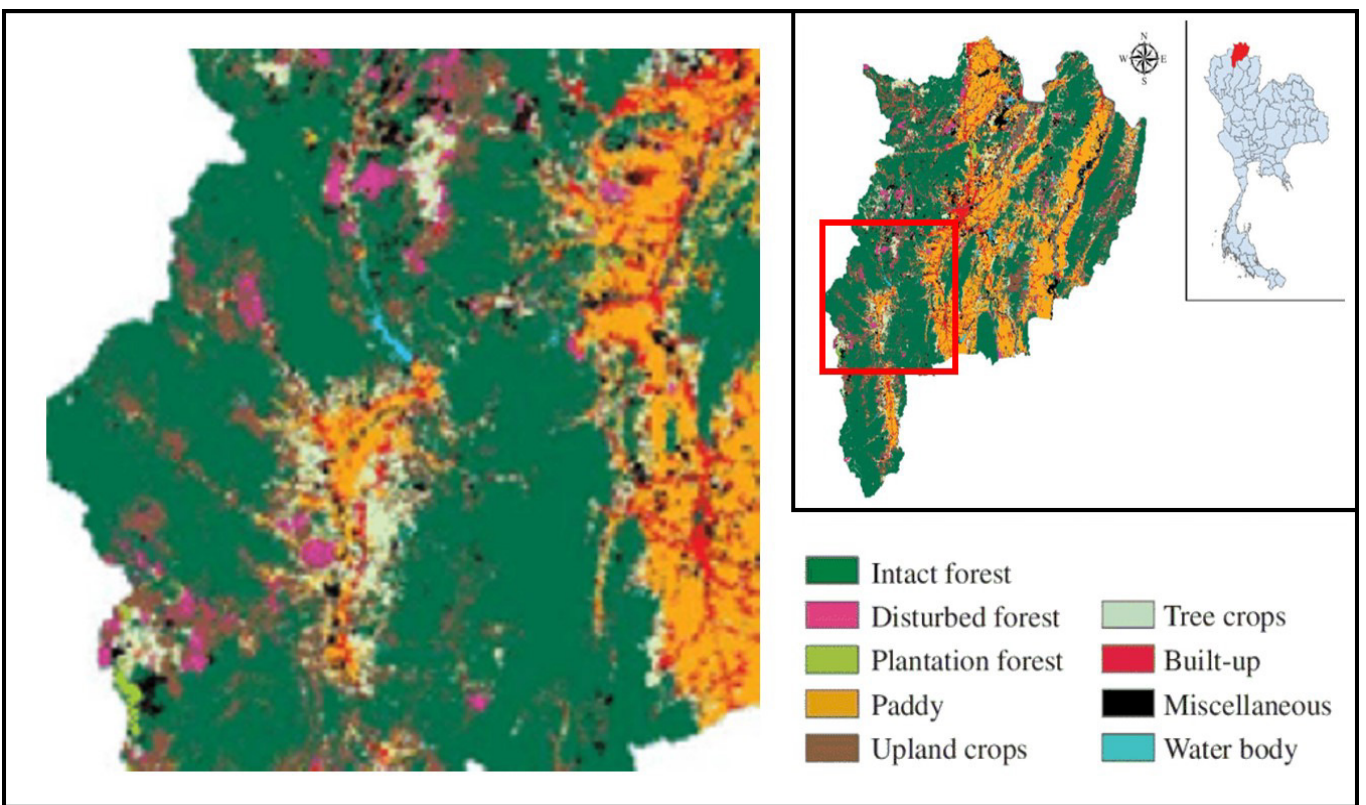

Figure 2. Location of Mae Suai dam and land use map for this simulation

Table 1

Manning's coefficients for land use type

\begin{tabular}{lccc}
\hline Land use type & Coefficient & Land use type & Coefficient \\
\hline Intact forest & 0.80 & Tree crops & 0.17 \\
Disturbed forest & 0.80 & Built-up & 0.011 \\
Plantation forest & 0.80 & Miscellaneous & 0.01 \\
Paddy field & 0.17 & Water body & 0.01 \\
Upland crops & 0.06 & & \\
\hline
\end{tabular}

of adaptive tree grid, set as follows. There were 4 tree grid level with resolutions $1800 \mathrm{~m} \times 1800 \mathrm{~m}, 360 \mathrm{~m} \times 360 \mathrm{~m}, 180 \mathrm{~m} \times 180 \mathrm{~m}$ and $90 \mathrm{~m} \times 90 \mathrm{~m}$ for levels $1,2,3$ and 4 , respectively. Therefore, level 1 had the initial grid containing $30 \times 30$ cells. The topography values were provided for levels 1-4. The tree grid cells for children were designed as $5 \times$ $5,2 \times 2$ and $2 \times 2$ for levels 1, 2 and 3, respectively, while level 4 cells had no children. The numerical experiment was simulated for 36,000 seconds with the boundary conditions defined as open boundaries.

In order to validate and evaluate the shallow water model and the program for dam break flood events, the program was used to simulate the water flow after the Xe-Pian dam break that occurred in Laos on 23 July 2018. We also simulated the Mae Suai dam-break flood for various initial water levels in the dam. 


\section{RESULTS}

\section{Xe-Pian Dam-Break Flood Simulation}

The simulation of Xe-Pian dam break was performed on the domain of digital terrain data 16,200 $\mathrm{m} \times 19,800 \mathrm{~m}$, generated from the Shuttle Radar Topography Mission (SRTM) data source. We assumed that the free surface elevation of the reservoir behind the dam was $805 \mathrm{~m}$. The whole process took 5 hours to simulate the first 24-hour period of the flood event. In this experiment, we defined the Manning's coefficient to be 0.035 , where the boundary condition is considered as open following Busaman (2014).

For the initial grid of the simulation, the finest grid cells were generated at the boundary of the reservoir. The maximum tree grid level was 4 with resolutions of 720 $\mathrm{m} \times 720 \mathrm{~m}, 360 \mathrm{~m} \times 360 \mathrm{~m}, 180 \mathrm{~m} \times 180 \mathrm{~m}$, and $90 \mathrm{~m} \times 90 \mathrm{~m}$ for levels $1,2,3$, and 4 , respectively. Therefore, the initial grid level 1 had $70 \times 95$ cells. The topography values were automatically obtained via the bilinear interpolation. The tree grid cells for children were $2 \times 2$ for level 1-3, while no children from level 4 cells.

The results are presented at different points in time as shown in Figure 3. The color bars at top left corner of each images indicate the depth of flooding (in meters). To check the accuracy of the model, we compared the simulation result with the satellite image as shown in Figure 4. The simulation of flooding area is nearly the same as that obtained from the satellite image. This suggests that the simulation program is reasonably accurate and has potential for practical usage.

\section{Mae Suai Dam-Break Flood Simulation}

We simulated the Mae Suai dam-break flood for various initial water levels in the dam. The initial minimum and maximum water levels from the mean sea level in the dam were set for each simulation from $472 \mathrm{~m}$ (lowest water level) to $509 \mathrm{~m}$ (spillway level). Therefore, the 38 SWE solution sets were simulated by adaptive grid finite volume method related to initial water level from 472 to $509 \mathrm{~m}$ using 1-meter increments for each simulation. Some examples of the dam-break simulation for different initial water levels in the dam are illustrated in Figure 5.

From Figure 5, it can be seen that the flood results depended on the initial water level in the dam. By this reasoning, we used the relation between polynomial modeling and simulation results to model the flood risk information regarding arrival times, maximum water depths and flood map. The details of the modeling and results are presented in the following section.

The simulation result, obtained by the SWE, were estimated using polynomial modeling (Equation 4). In Figure 6, comparisons between the polynomial models and the SWE simulation results are shown for arrival times (left panel) and maximum water depth 


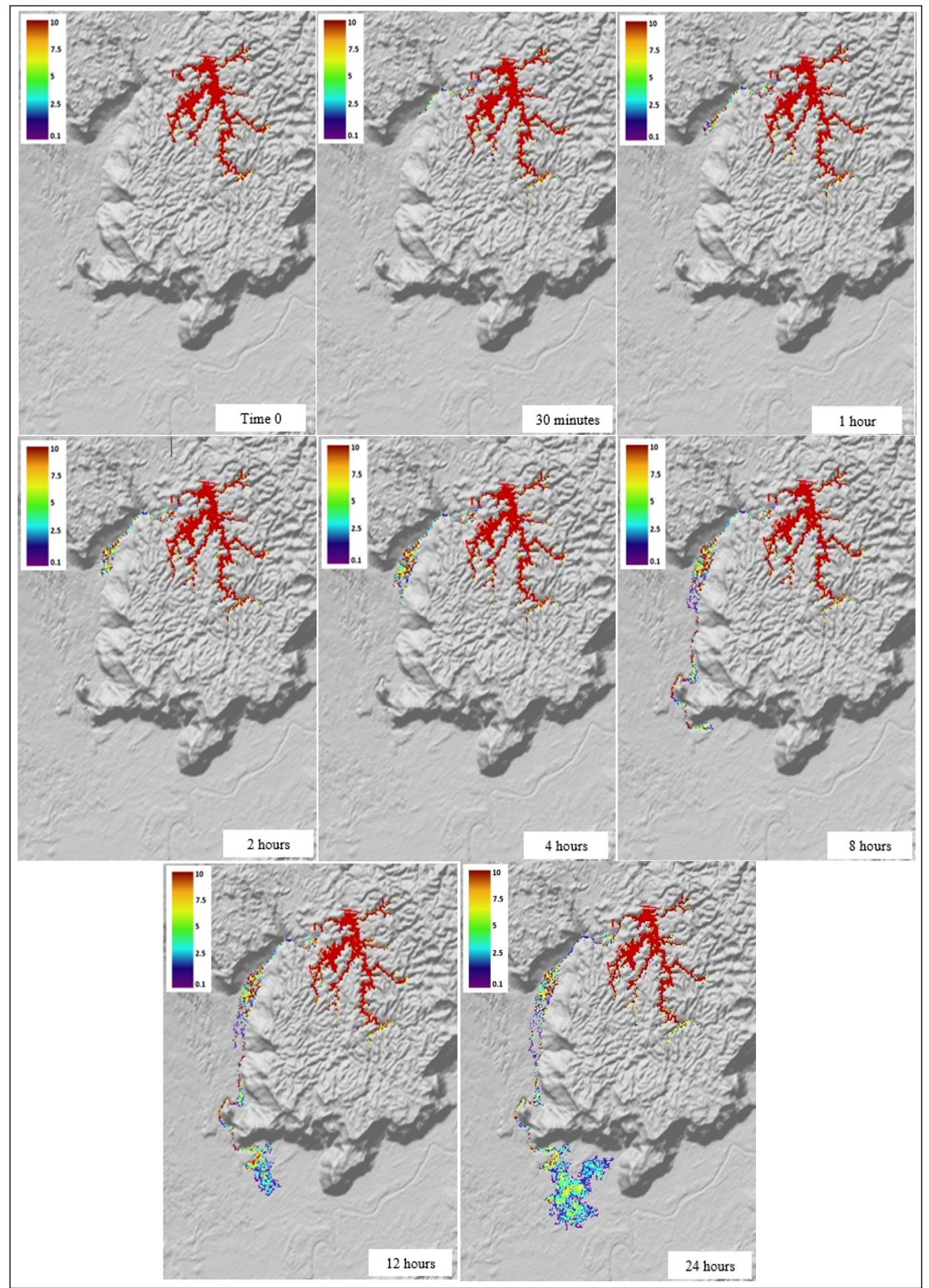

Figure 3. Simulation results of Xe-pian dam break at different points in times $(0,30$ minutes, 1 hour, 2 hours, 4 hours, 8 hours, 12 hours and 24 hours). Depth of flooding (in meters) is shown in the legends 


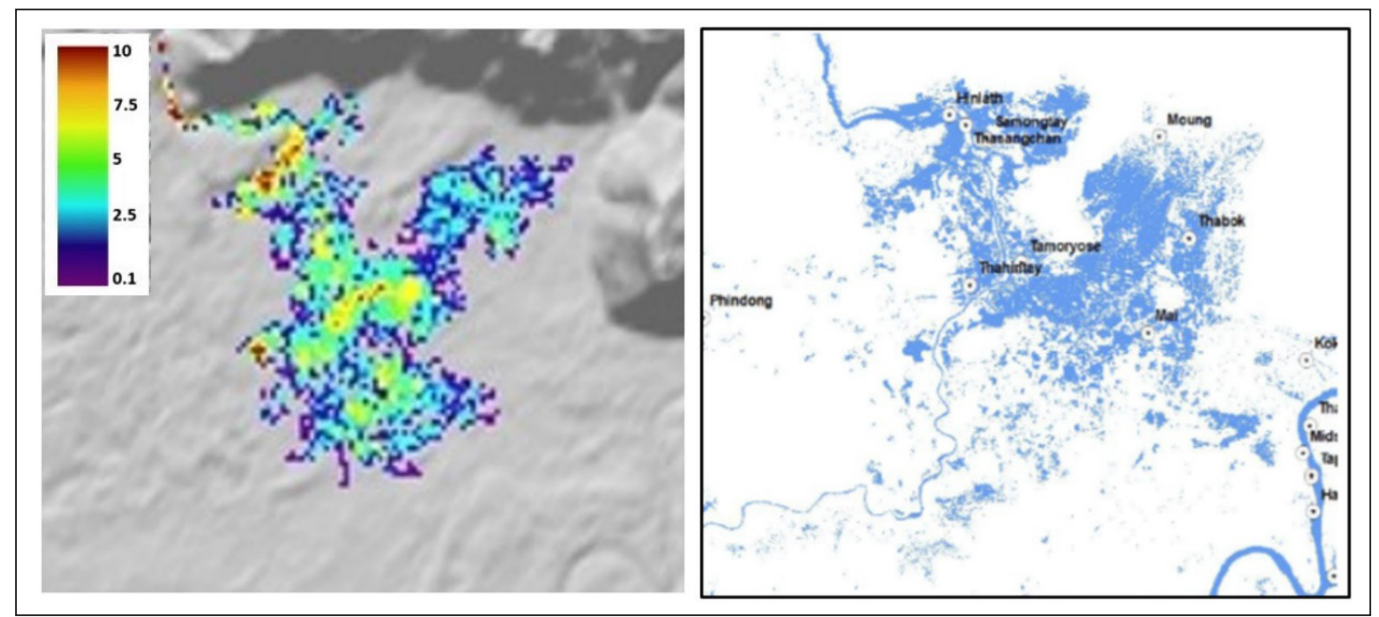

Figure 4. Comparison of the numerical simulation (left) and the satellite image (right) for the Xe-Pian dam break in Laos

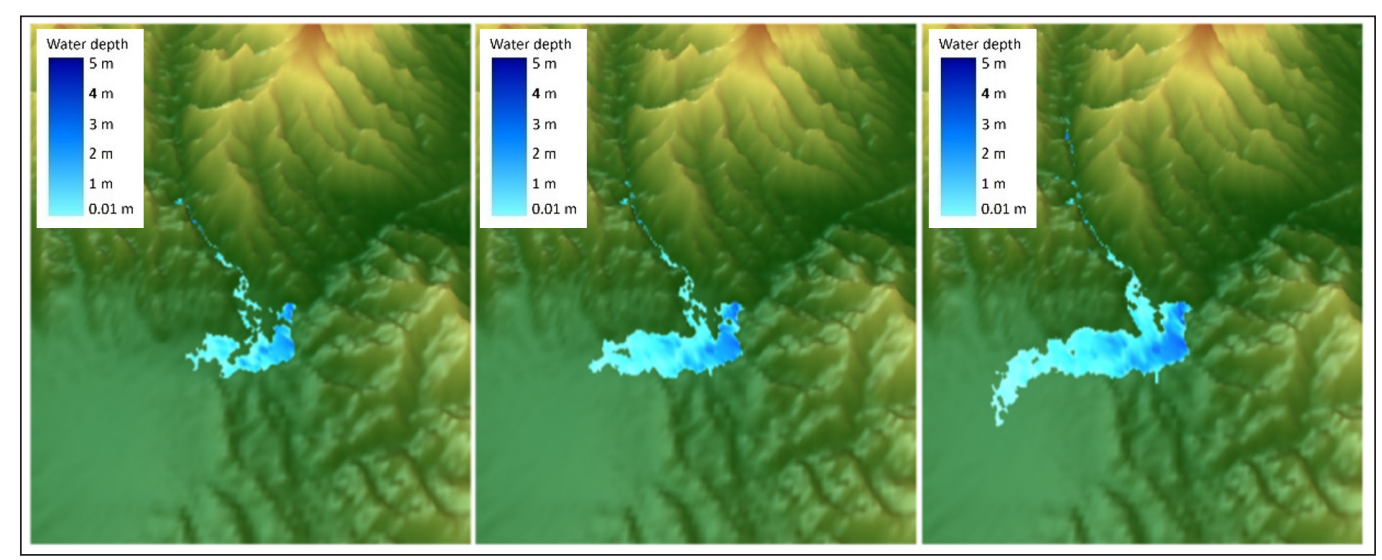

Figure 5. 3D visualization of dam-break flow simulation at 36000 seconds for different initial water levels: $490 \mathrm{~m}$ (left), $500 \mathrm{~m}$ (middle) and $509 \mathrm{~m}$ (right).

(right panel). Figure 6 shows that the arrival times and the maximum water depth from the polynomial model are consistent with the SWE simulation.

In this section, the results of the flood map prediction are presented. We used the polynomial models to predict and visualize the flood map of Mae Suai dam break for an initial water level in the dam set at 505.5 meters. To assess the accuracy of the SWE simulation, the color in each grid cell was compared with each corresponding grid cell from the flood map created by the polynomial model. The comparison is that if the simulation time is greater than the flow arrival time at the cell, the flood area is expanded to the cell, and colored by its maximum water depth value. Figure 7 shows results for the polynomial model at various time points compared with the SWE simulation. As the two results are very similar, the polynomial model can be used to predict areas at high risk of flooding. 
For quantitative comparison, we calculated the mean relative absolute error between the polynomial model and the SWE simulation for arrival time and maximum water depth. The mean relative absolute error of arrival time was $12.01 \%$, while maximum water depth was

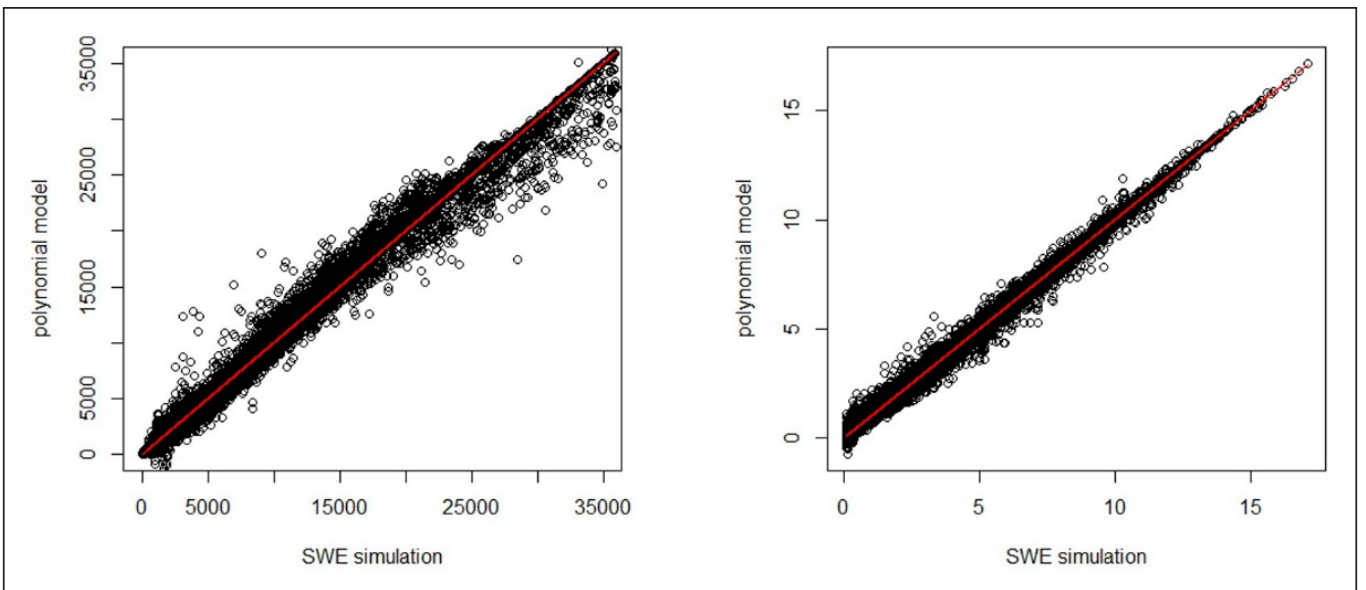

Figure 6. Comparison of arrival times (left) and maximum water depths (right) obtained by the polynomial model and the SWE simulation.

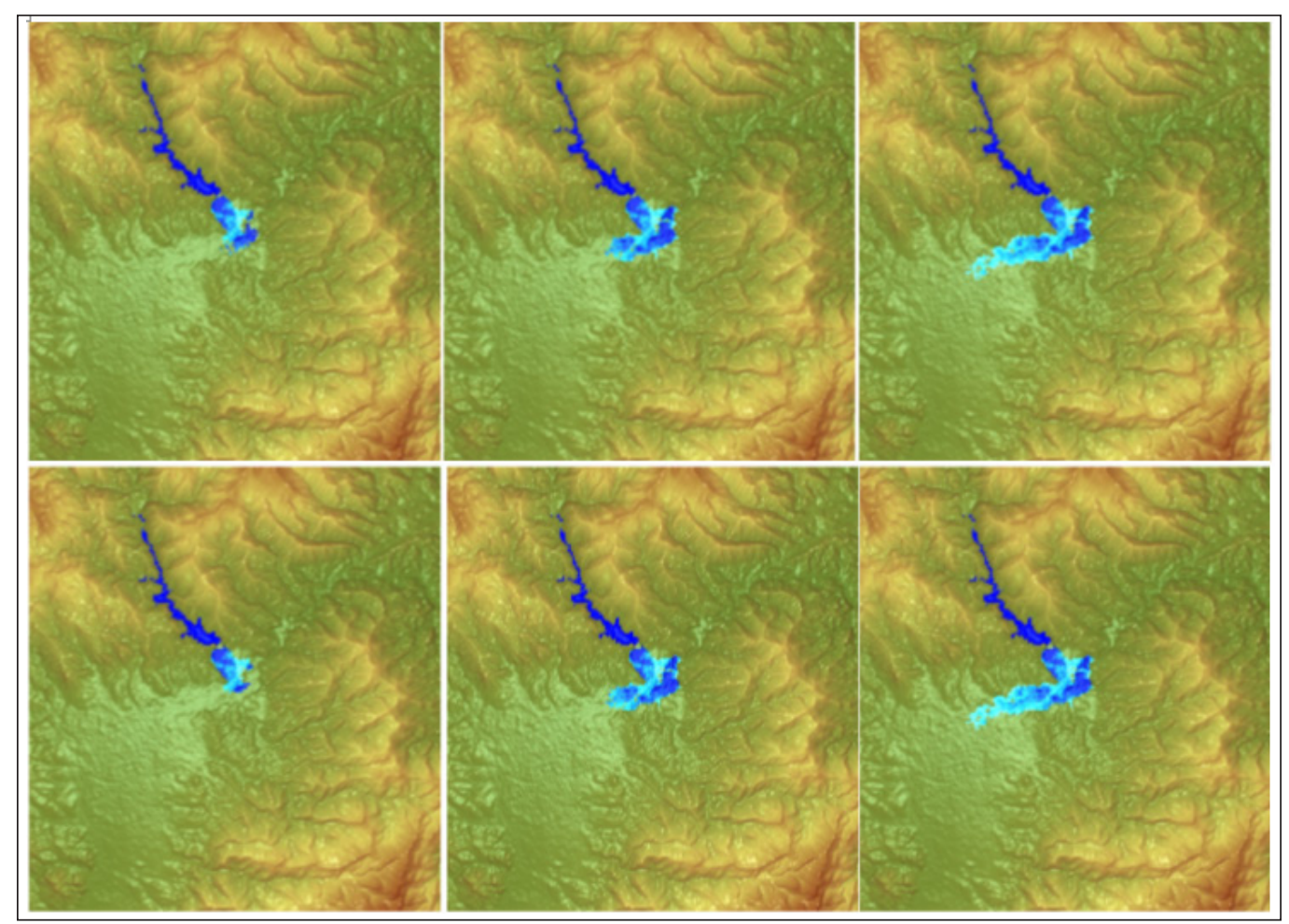

Figure 7. Visualization of flood map using polynomial model (top) and SWE simulation (bottom) for each time point: 1500 second (left), 6,000 second (middle), 36,000 second (right) 
$2.81 \%$. Thus, the accuracy of the polynomial model compared with the SWE simulation was $87.99 \%$ for arrival time results and $97.19 \%$ for maximum water depth results.

\section{CONCLUSION}

In this study, we validated the shallow water equations with an adaptive tree grid finite volume algorithm using the Xe-pian dam-break flood simulation. The numerical results of the water propagation was in agreement with the satellite image. This shows that the numerical algorithm has the potential for dam-break flood simulations. The numerical algorithm can thus be used to simulate the Mae Suai dam-break flood for various initial dam water levels. The result sets were approximated using a polynomial model and the results were similar to the results from the SWE. Moreover, the flood risk map can be generated using the arrival times and maximum water depths models. A comparison of the flood risk map created by the polynomial and SWE models were similar, indicating that the polynomial model can be useful for Mae Suai dam-break flood risk assessment and flood preparation. The proposed method is more efficient and a flood risk map can be obtained without the need to fully solve the shallow water equations. The method can also be applied for other dams and floods in regions where information of that area is available.

\section{ACKNOWLEDGMENTS}

We would like to thank the Centre of Excellence in Mathematics, the Commission on Higher Education, Thailand for supporting this research.

\section{REFERENCES}

Audusse, E., Buchut, F., Bristeau, M. O., Klein, R., \& Perthame, B. (2004). A fast and stable well-balanced scheme with hydrostatic reconstruction for shallow water flows. SIAM Journal on Scientific Computing, 25(6), 2050-2065. doi: 10.1137/S1064827503431090

Busaman, A. (2014). Dynamically adaptive tree grid technique for flood simulation (Doctoral thesis). Chulalongkorn University, Bangkok, Thailand.

Busaman, A., Mekchay, K., Siripant, S., \& Chuai-Aree, S. (2015). Dynamically adaptive tree grids modeling for simulation and visualization of rain-water overland flow. International Journal for Numerical Methods in Fluids, 79(11), 559-579. doi: https://doi.org/10.1002/fld.4064

Cushman-Roisin, B., \& Beckers, J. M. (2011). Introduction to geophysical fluid dynamics: Physical and numeric aspects. Oxford, UK: Academic Press.

Dat, T. T., Tri, D. Q., Truong, D. D., \& Hoa, N. N. (2019). Application of mike flood model in inundation simulation with the Dam-break Scenarios: A case study of Dak-Drinh Reservoir in Vietnam. International Journal of Earth Sciences and Engineering, 12(01), 60-70. doi: 10.21276/ijee.2019.12.0106 
Delestre, O., Cordier, S., James, F., \& Darboux, F. (2008, June 9-13). Simulation of rain-water overland-flow. In Proceedings of the 12th International Conference on Hyperbolic Problems (pp. 537-546). University of Maryland, College Park, USA.

George, D. L. (2011). Adaptive finite volume methods with well-balanced Riemann solvers for modeling floods in rugged terrain: Application to the Malpasset dam-break flood (France, 1959). International Journal for Numerical Methods in Fluids, 66(8), 1000-1018. doi: https://doi.org/10.1002/fld.2298

Gong, L. (2018). Laos dam collapse: Regional response. Khmer Times. Retrieved August 23, 2019, from https:// www.khmertimeskh.com/525750/laos-dam-collapse-regional-response

Goodman, R. (2013). On the failure of Malpasset Dam. AEG Shlemon specialty Conference: Dam failures and incidents. Denver, Colorado: Association of Environmental and Engineering Geologists.

Hagen, T. R., Hjelmervik, J. M., Lie, K. A., Natvig, J. R., \& Henriksen, M. O. (2005). Visual simulation of shallow water waves. Simulation Modelling Practice and Theory: Special Issue on Programmable Graphics Hardware, 13(8), 716-726. doi: https://doi.org/10.1016/j.simpat.2005.08.006

Hunukumbura, P. B., Weerakoon, S. B., \& Herath, S. (2007). Development of a cell-based model to derive direct Runoff Hydrgraphs for Ungauged mountainous basins. Journal of Mountain Science, 4(4), 309-320. doi: https://doi.org/10.1007/s11629-007-0309-8

Latrubesse, E. M., Park, E., Sieh, K., Dang, T., Lind, Y. N., \& Yun, S. (2020). Dam failure and a catastrophic flood in the Mekong basin (Bolaven Plateau), southern Laos, 2018. Geomorphology, 362, 1-16. doi: https://doi.org/10.1016/j.geomorph.2020.107221

NOAA. (2005). Taum Sauk dam failure December 15th 2005. National Weather Service St. Louis Missouri. Retrieved December 1st, 2019, from https:/www.weather.gov/media/1sx/Events/12_15_2005.pdf

Yamaguchi, S., Ikeda, T., Iwamura, K., Naono, K., Ninomiya, A., Tanaka, K., \& Takahashi, H. (2007, September 4-5). Development of GIS-based flood-simulation software and application to flood-risk assessment. In 2nd IMA International Conference on Flood Risk Assessment (pp. 4-5). University of Plymouth, UK.

Zanotti, O., \& Manca, G. M. (2010). A very short introduction to Godunov methods. Caen, France: Lecture Notes for the COMPSTAR School on Computational Astrophysics. 